\title{
Nonlinear Regression Based Health Monitoring of Hysteretic Structures under Seismic Excitation
}

\author{
C. Xu, ${ }^{1}$ J. Geoffrey Chase, ${ }^{2}$ and Geoffrey W. Rodgers ${ }^{2}$ \\ ${ }^{1}$ School of Astronautics, Northwestern Polytechnical University, Xian 710072, China \\ ${ }^{2}$ Department of Mechanical Engineering, University of Canterbury, Private Bag 4800, Christchurch 8140, New Zealand
}

Correspondence should be addressed to C.Xu; chao_xu@nwpu.edu.cn

Received 19 March 2015; Revised 25 June 2015; Accepted 29 June 2015

Academic Editor: Mickaël Lallart

Copyright (C) 2015 C. Xu et al. This is an open access article distributed under the Creative Commons Attribution License, which permits unrestricted use, distribution, and reproduction in any medium, provided the original work is properly cited.

\begin{abstract}
This paper presents a health monitoring method using measured hysteretic responses. Acceleration and infrequently measured displacement are integrated using a multirate Kalman filtering method to generate restoring force-displacement hysteresis loops. A linear/nonlinear regression analysis based two-step method is proposed to identify nonlinear system parameters. First, hysteresis loops are divided into loading/unloading half cycles. Multiple linear regression analysis is applied to separate linear and nonlinear half cycles. Preyielding stiffness and viscous damping coefficient are obtained in this step and used as known parameters in the second step. Then, nonlinear regression analysis is applied to identified nonlinear half cycles to yield nonlinear system parameters and two damage indicators: cumulative plastic deformation and residual deformation. These values are closely related to structural status and repair costs. The feasibility of the method is demonstrated using a simulated shear-type structure with different levels of added measurement noise and a suite of ground motions. The results show that the proposed SHM method effectively and accurately identifies physical system parameters with up to $10 \%$ RMS added noise. The resulting damage indicators can robustly and clearly indicate structural condition over different earthquake events.
\end{abstract}

\section{Introduction}

Whenever a strong motion earthquake occurs, buildings are expected to remain standing with various degrees of damage. Critical decisions must be made within a short period of time concerning whether the buildings are suitable for continued occupancy. Vibration-based structural health monitoring (SHM) has gained much interest and attention in the civil engineering community in recent years. It is recognised as a powerful tool to identify damage at its earliest stage and to determine the residual useful life of structures, especially for rapid evaluation after a major event [1].

Many vibration-based SHM methods for civil structures are based on identifying changes in modal characteristics [25]. However, only low frequency modes related to structural global deformation can be measured accurately, and these modal parameters are insensitive to localized damage in some cases and typically more applicable to structures where vibration response is highly linear [6]. Local diagnostic methods, such as impedance-based [7] and guided-wave based [8] methods, have been developed to improve sensitivity to local failure modes. However, they rely on close proximity to damage location and typically require many sensors distributed throughout a structure, which is currently impractical.

Advanced signal processing tools, such as wavelet analysis [9], empirical mode decomposition, and Hilbert transform [10], are also being proposed. These techniques offer the advantage of determining both the location and time of the damage. However, they cannot directly identify physical system parameters and quantify the level of nonlinear damage due to the absence of a physical system model. Therefore, a number of model-based system identification methods have been presented, including a range of time-domain filters to track time-variant model parameters [11-18]. However, only a few address nonlinear hysteresis and hysteresis-based damage indicators [19].

Hysteretic behaviour plays a critical role not only in seismic performance-based analysis and design [20, 21], but also in capturing the nonlinear yielding and energy 
absorption associated with damage [22]. A SHM method that captures hysteretic response would give more insight into structural nonlinearity and quantify the level of nonlinear damage.

Structural restoring force-displacement hysteresis loops can be constructed from measured responses [23-25]. Accelerometers are the most commonly used instruments in civil structures, and displacement and velocity have to be obtained from numerical integration. This procedure is fraught with major pitfalls due to the effects of noise, limiting accuracy of the hysteretic loops and damage detection methods based on hysteresis monitoring. However, recent advances in low-rate displacement sensors, such as GPS [26], enable sensor fusion methods that deliver accurate displacement, velocity, and acceleration. Several sensor fusion methods, such as the multirate Kalman filtering method [27], the cubic spline displacement correction method [28], the finite difference FIR filter method [29], and the finite element FIR filter method [30], have been proposed. These methods are expected to suppress measurement noise effectively and yield high quality hysteresis loops.

Structural damage indicators can be further extracted from constructed hysteresis loops. Secant stiffness was first calculated to determine the occurring of degradation and damage in [31]. System effective stiffness was extracted to describe the evolution of the structural stiffness in [32]. Evolution of hysteresis loop shape was considered as a rapid visual indicator of system degrading in [33]. Although these damage indicators can be used to indicate the occurrence of damage, they are largely qualitative. Damage indicators that can quantify structural damage and closely related to structural postevent safety and repair costs are urgently needed.

This research presents a simple and novel health monitoring method for hysteretic structures subjected to seismic excitation. A multirate Kalman filtering technique is applied to estimate high quality displacement and velocity from high-rate sampled acceleration and low-rate sampled displacement data. Hysteresis loops are constructed and a regression analysis based two-step method is proposed to identify preyielding, viscous damping coefficient, yielding displacement and postyielding stiffness, and resulting nonlinear damage indicators. The feasibility and robustness of the proposed method are illustrated for different noise levels over a suite of earthquake events.

\section{Construction of Hysteresis Loops}

Toussi and Yao [23] first presented the idea of generating system hysteresis loops from recorded seismic response data. For this proof-of-concept study, it will be assumed that the structure in question can be adequately modelled as a singledegree-freedom (SDOF) system for simplicity and clarity. This situation is also true if the test structure responds primarily in a single mode and can be defined:

$$
m \ddot{x}+f(x, \dot{x})=-m \ddot{x}_{g},
$$

where $x, \dot{x}$, and $\ddot{x}$ are displacement, velocity, and acceleration related to the ground; $f$ is the total restoring force; $\ddot{x}_{g}$ is ground acceleration; and $m$ is the mass.

Rewriting (1) and including viscous damping restoring force yield

$$
f(x, \dot{x})=-m\left[\ddot{x}_{g}+\ddot{x}\right]=-m u=c \dot{x}+f_{s}(x, \dot{x}),
$$

where $u$ is absolute acceleration; $c$ is viscous damping coefficient; and $f_{s}(x, \dot{x})$ is stiffness restoring force. Assuming $m$ to be known a priori and $u$ to be measured, $f$ is consequently obtained. Dynamic displacement and velocity can be obtained from measured sensor data by integration and correction. Thus, hysteresis loops can be constructed by graphing the restoring force versus displacement with time as an implicit parameter.

Direct integration of measured acceleration to obtain velocity and displacement is sensitive to noise and can cause significant distortion of estimated displacement [34]. Data fusion of high-rate acceleration and low-rate displacement measurements can effectively suppress noise and yield good estimates of velocity and displacement. If high-rate acceleration and low-rate displacement measurements are available, estimation of displacement and velocity from the measurements can be modelled by a discrete dynamic system:

$$
\begin{aligned}
\mathbf{x}_{k+1} & =\mathbf{A}^{s} \mathbf{x}_{k}+\mathbf{B}^{s} u_{k}+\boldsymbol{\alpha}_{k}, \\
z_{k} & =\mathbf{H}_{k} \mathbf{x}_{k}+\boldsymbol{\beta}_{k},
\end{aligned}
$$

where (3) is the system equation and (4) is the observation equation; $u_{k}$ is the measured acceleration and $z_{k}$ is the measured displacement. The state vector $\mathbf{x}_{k}$ comprises the displacement $d_{k}$ and the velocity $v_{k}$; that is,

$$
\mathbf{x}_{k}=\left[\begin{array}{l}
d_{k} \\
v_{k}
\end{array}\right] .
$$

Note that the subindex $k$ indicates a progression in time. $\mathbf{A}^{s}$ is a $2 \times 2$ matrix describing the system dynamics, $\mathbf{B}^{s}$ is $2 \times 1$ input matrix, and $\mathbf{H}_{k}$ is $1 \times 2$ design matrix, defined as

$$
\begin{aligned}
\mathbf{A}^{s} & =\left[\begin{array}{ll}
1 & \tau_{a} \\
0 & 1
\end{array}\right] ; \\
\mathbf{B}^{s} & =\left[\begin{array}{c}
\frac{\tau_{a}^{2}}{2} \\
\tau_{a}
\end{array}\right] ; \\
\mathbf{H}_{k} & =\left[\begin{array}{ll}
1 & 0
\end{array}\right],
\end{aligned}
$$

where $\tau_{a}$ is the acceleration sampling interval. In (3) and (4), $\boldsymbol{\alpha}$ is a vector of acceleration measurement noise with distribution $\left(\mathbf{0}, \mathbf{Q}^{s}\right)$ and $\boldsymbol{\beta}$ is the vector of displacement measurement noise with distribution $\left(\mathbf{0}, \mathbf{R}^{s}\right)$. Both are assumed 
to be Gaussian white noise processes with covariance $q$ and $r$. Thus, $\mathbf{Q}^{s}$ and $\mathbf{R}^{s}$ are given by

$$
\begin{aligned}
& \mathbf{Q}^{s}=\left[\begin{array}{cc}
\frac{q \tau_{a}^{3}}{3} & \frac{q \tau_{a}^{2}}{2} \\
\frac{q \tau_{a}^{2}}{2} & q \tau_{a}
\end{array}\right] ; \\
& \mathbf{R}^{s}=\frac{r}{\tau_{d}},
\end{aligned}
$$

where $\tau_{d}$ is the displacement sampling interval.

With (3) to (7), a discrete time multirate Kalman filter can be used to estimate the displacement and velocity at each acceleration sampling instant $[27,35]$.

\section{SHM Based on Regression Analysis of Hysteresis Loops}

Many civil structures exhibit hysteresis when subject to severe cyclic loading. Figure 1 shows general hysteretic loops without considering system stiffness or strength degradation. A hysteretic cycle consists of a loading and an unloading half cycle. Any loading/unloading half cycle can be further divided into two nearly linear regimes: elastic and plastic, governed by $k_{e}$, the preyielding stiffness, and $k_{p}$, the postyielding stiffness, respectively. The elastic-plastic transition is generally smooth and gradual, but small. Omitting the transition process, the original half cycle can be represented by two line segments with different slopes, as shown in Figure 1, to capture the essential system dynamics.

If the approximated two lines and their interaction point are found, the nonlinear plastic deformation during the half cycle can be easily calculated. Damage indicators related to postevent structural safety and repair costs, such as residual deformation and cumulative plastic deformation, can then be directly obtained by summing identified nonlinear deformation from all half cycles. Thus, the SHM problem is converted to a search for this approximation for each half cycle.

Hysteretic loops can be divided into many loading or unloading half cycles by identifying the points where the sign of the velocity changes. During a seismic event, structural behaviour is linear for most half cycles and nonlinear for fewer others. For linear half cycles, a single segment line approximation is enough. For nonlinear half cycles, a broken line approximation is needed. Hence, a two-step approximation method is developed to optimally approach the original half cycle. In the first step, linear and nonlinear half cycles are separated. In the second step, identified nonlinear half cycles are further estimated.

Regression analysis is a powerful tool for modelling the relationship between a dependent variable and one or more independent variables [36]. Recalling (2), displacement $x$ and velocity $\dot{x}$ are defined as the independent variables and restoring force $f$ is defined as the dependent variable. Thus, the optimal approximation of each half cycle formulates a regression problem.

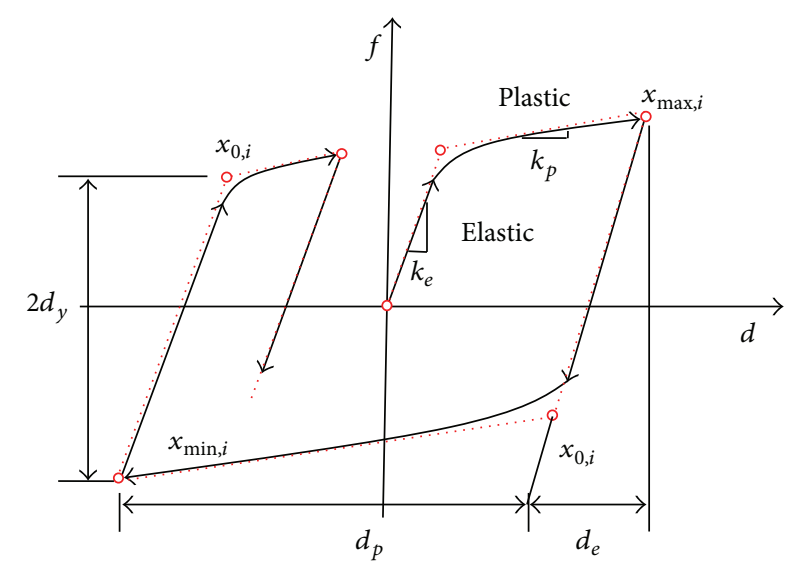

FIGURE 1: Hysteretic loops for arbitrary response.

3.1. Step 1: Linear Regression to Each Half Cycle. Multiple linear regression is applied to each half cycle. It is equal to using an equivalent linear system assumption to each half cycle. Thus, (2) can be rewritten:

$$
-m\left[\ddot{x}_{g}+\ddot{x}\right]=c_{l} \dot{x}+k_{l} x,
$$

where $k_{l}$ is the effective system stiffness and $c_{l}$ is the effective system damping. All observation variables $\left(x, \dot{x}, \ddot{x}, \ddot{x}_{q}\right)$ can be obtained directly or indirectly from measurements. Structural mass is assumed to be known a priori. Equation (8) holds at each sampling instant $k$, with variables defined:

$$
\begin{aligned}
y_{k} & =-m\left[\ddot{x}_{g k}+\ddot{x}_{k}\right], \\
x_{1, k} & =\dot{x}_{k}, \\
x_{2, k} & =x_{k} .
\end{aligned}
$$

The optimal approximation problem can be formulated as

$$
\mathbf{Y}=\mathbf{X} \boldsymbol{\beta}+\boldsymbol{\epsilon},
$$

$$
\mathbf{Y}=\left\{\begin{array}{c}
y_{1} \\
y_{2} \\
\vdots \\
y_{k} \\
\vdots \\
y_{n}
\end{array}\right\} \text {, }
$$

$$
\mathbf{X}=\left[\begin{array}{ccc}
1 & x_{1,1} & x_{2,1} \\
1 & x_{1,2} & x_{2,2} \\
\vdots & \vdots & \vdots \\
1 & x_{1, k} & x_{2, k} \\
\vdots & \vdots & \vdots \\
1 & x_{1, n} & x_{2, n}
\end{array}\right],
$$




$$
\begin{gathered}
\boldsymbol{\beta}=\left\{\begin{array}{c}
\beta_{0} \\
\beta_{1} \\
\beta_{2}
\end{array}\right\}, \\
\boldsymbol{\epsilon}=\left\{\begin{array}{c}
\epsilon_{1} \\
\epsilon_{2} \\
\vdots \\
\epsilon_{k} \\
\vdots \\
\epsilon_{n}
\end{array}\right\},
\end{gathered}
$$

where $n$ is the number of all observed response variable pairs, $\mathbf{Y}$ is regressand, $\mathbf{X}$ is the repressor, $\boldsymbol{\beta}$ is the regression coefficients vector to be estimated, and $\epsilon$ is the vector of estimation error due to measurement noise and model error and is random and normally distributed. The least squares method then finds the unbiased estimates of the regression coefficients:

$$
\left(b_{0}, b_{1}, b_{2}\right)=\underset{\boldsymbol{\beta}}{\arg \min }\left[(\mathbf{Y}-\mathbf{X} \boldsymbol{\beta})^{\prime}(\mathbf{Y}-\mathbf{X} \boldsymbol{\beta})\right]
$$

where the vector $\left(b_{0}, b_{1}, b_{2}\right)$ is the estimates of the regression coefficients of $\left(\beta_{0}, \beta_{1}, \beta_{2}\right)$.

Comparing (10a), (10b) and (8), it is clear that the least squares estimates, $b_{1}$ and $b_{2}$, are the effective linear system damping and the effective stiffness coefficient, respectively. When there is no plastic deformation presented in the half cycle, $k_{l}$ should approach the system true preyielding elastic stiffness, $k_{e}$, and when there is nonlinear plastic deformation, $k_{l}$ should capture a secant average stiffness of $k_{e}$ and $k_{p}$. Therefore, $k_{l}$ is similar to the secant stiffness in [31] but derived in a least squares sense here.

The estimated equivalent stiffness $k_{l}$ can vary over different half cycles. Varying $k_{l}$ is a significant indicator of the nature of the dynamic system. It is reasonable that the hysteresis curve is linear when the half-cycle displacement increment $\Delta d$ is small and nonlinear when $\Delta d$ is larger than the structural yield displacement. A rapid drop in $k_{l}$ at large displacement increment can be viewed as a good indicator of occurring inelastic behaviour during that half cycle. Thus, the plot of $k_{l}$ versus $\Delta d$ will be used to identify the potential nonlinear half cycle.

In addition, the estimated equivalent linear damping coefficient $c_{l}$ is the measure of system energy dissipation. System energy dissipation capacity will increase due to the added hysteretic damping. The plot of $c_{l}$ versus $\Delta d$ may also be used as another indicator of the inelastic half cycles. Thus, linear and nonlinear half cycles can be separated by using a threshold determined from these indicators.

For all identified linear half cycles, the multiple linear regression process yields many estimates of viscous damping coefficient $c$ and preyielding elastic stiffness $k_{e}$. The statistical mean of $c$ and $k_{e}$ over all these linear half cycles will be considered "true" values and be used as known parameters for the next step.

3.2. Step 2: Nonlinear Regression Analysis to Identified Nonlinear Half Cycles. The postyielding stiffness is typically about a $5-10 \%$ of preyielding stiffness for many civil structures. Thus, the slope of the hysteresis curve for a nonlinear half cycle will undergo sudden change. To optimally approximate the nonlinear half cycles, data points in these nonlinear half cycles must be divided into multiple segments and regress a different linearly parameterized polynomial for each segment. $k_{e}$ and $k_{p}$ can be obtained directly from estimated regression coefficients. The difficulty is associated with the unknown interaction point of each segment and the joint point of the segmented regression lines has to be estimated. It is actually a special nonlinear regression problem, named multiphase linear regression.

This nonlinear regression problem has a long history in mathematics [37-39] and has been applied in some engineering fields [40]. However, it has not been used extensively in civil engineering. Let $\left(x_{k}, y_{k}\right), k=1, \ldots, n$, be $n$ pairs of observation values of displacement and the restoring force within a nonlinear half cycle. Because the viscous damping coefficient $c$ is estimated from the first identification step, the stiffness restoring force can be calculated:

$$
f_{s}(x, \dot{x})=-m\left[\ddot{x}_{g}+\ddot{x}\right]-\widetilde{c} \dot{x},
$$

where $\tilde{c}$ is the estimated viscous damping coefficient from the first step. To optimally approximate the nonlinear half cycles, a multiphase linear regression model can be defined:

$$
\begin{array}{ll}
f_{1}=a_{1} x+b_{1}, & x_{1} \leq x \leq x_{0}, \\
f_{2}=a_{2} x+b_{2}, & x_{0}<x \leq x_{n},
\end{array}
$$

where $\boldsymbol{\alpha}=\left\{a_{1}, b_{1}, a_{2}, b_{2}\right\}^{T}$ is the set of the unknown regression coefficients of each segment and $x_{0}$ is the unknown interaction point. The interaction point satisfies the linear constraint to ensure the continuity of the solution at the interaction point:

$$
a_{1} x_{0}+b_{1}=a_{2} x_{0}+b_{2} \text {. }
$$

Using a least squares method, it is possible to seek the best estimate of the vector $\boldsymbol{\alpha}$, which minimizes the residual sum

$$
\begin{aligned}
R(\boldsymbol{\alpha})= & \sum_{x_{1} \leq x_{k} \leq x_{0}}\left[y_{k}-\left(a_{1} x_{k}+b_{1}\right)\right]^{2} \\
& +\sum_{x_{n} \geq x_{k}>x_{0}}\left[y_{k}-\left(a_{2} x_{k}+b_{2}\right)\right]^{2}
\end{aligned}
$$

and is subject to the constraint (14).

To minimize the function $R(\boldsymbol{\alpha})$, a method similar to the one implemented in [40] is used here. Conceptually, if the transition point is known, the minimum of $R(\boldsymbol{\alpha})$ can be found by computing a standard linear regression for each segment. Thus, given a specific division between data points $I$ and $I+1$, the residual sum can be minimized over $\widetilde{\boldsymbol{\alpha}}_{I}=$ 
$\left\{a_{1}, b_{1}, a_{2}, b_{2}\right\}^{T}$, and this outcome yields a sequence of residual sum functions $R_{I}(\boldsymbol{\alpha})(I=2, \ldots, n-2$,$) . The goal is to pick$ $I$ that gives the minimum value for $R_{I}(\boldsymbol{\alpha})$. Note that this is true only when $x_{I} \leq x_{0} \leq x_{I+1}$. The estimator of $x_{0}$ has to be computed using the linear constraint (14) from the elements of $\widetilde{\boldsymbol{\alpha}}_{I}$ to check that $x_{0}$ is in fact between the two data points $I$ and $I+1$ to ensure the solution is the final solution. Using the proposed nonlinear regression analysis method, each nonlinear half cycle is approached by a two-segment broken line. This process yields the estimates of postyielding stiffness and yielding turning point on each nonlinear half cycle.

3.3. Damage Indicators. Information obtained from the proposed two-step method can be used to derive important damage indicators related to damage severity and repair cost of the target structure. In particular, consider the following:

(1) The preyielding and postyielding stiffness, $k_{e}$ and $k_{p}$, give good approximation of the actual system mechanical behaviour. $k_{p}$ clearly indicates the system residual load carrying capacity after yielding. The $k_{p}$ to $k_{e}$ ratio, like bilinear factor $\alpha$, can be used as a damage indicator to represent the sacrificial or residual stiffness during seismic events. Finally, changes in $k_{p}$ and $k_{e}$ over time indicate system stiffness/strength degradation.

(2) The yielding turning points identified in Step 2 are related to system yield deformation, $d_{y}$. It can be seen from Figure 1 that, for an unloading half cycle $i$,

$$
d_{y i}=\frac{x_{\max , i}-x_{0, i}}{2}
$$

where $x_{\max , i}$ is the displacement history maximum during the half cycle and $x_{0, i}$ is estimated interaction point of the half cycle $i$. For a loading nonlinear half cycle $i$,

$$
d_{y i}=\frac{x_{0, i}-x_{\min , i}}{2}
$$

where $x_{\min , i}$ is the displacement history minimum during the half cycle $i$.

(3) Cumulative plastic deformation can be used to capture the accumulation of damage sustained during dynamic loading. It can be calculated by summing the absolute plastic deformation over all nonlinear half cycles. The nonlinear plastic deformation $d_{p}$ for an unloading half cycle $i$ can be calculated:

$$
d_{p i}=\left(x_{\min , i}-x_{0, i}\right)\left(1-\frac{k_{p}}{k_{e}}\right),
$$

and for a loading half cycle $i$,

$$
d_{p i}=\left(x_{\max , i}-x_{0, i}\right)\left(1-\frac{k_{p}}{k_{e}}\right) .
$$

Thus, the cumulative plastic deformation $d_{\text {net }}$ is defined:

$$
d_{\mathrm{net}}=\sum_{i=1}^{n l}\left|d_{p i}\right|
$$

and the residual deformation $d_{\text {rel }}$ is defined:

$$
d_{\mathrm{rel}}=\sum_{i=1}^{n l} d_{p i}
$$

where $n l$ is the number of identified half cycles.

Other damage indices may also be easily obtained based on identified parameters. The more important point is that, with the estimated physical system parameters, model validation and response prediction for future seismic event are also possible, which will give a further critical reference for evaluation of structural safety and repair costs. Finally, quantified knowledge of these values could provide a better foundation for decision making by building owners, tenants, and insures, reducing debate and speeding up recovery.

\section{Simulated Proof-of-Concept Structure}

The simulated proof-of-concept structure is a SDOF moment-resisting frame model of a five-story building shown in Figure 2. The seismic weight per floor is $1692 \mathrm{kN}$ for the roof level and $2067 \mathrm{kN}$ for all other levels. The frame system is designed using the displacement-based design approach to sustain a target drift of $2 \%$ under a 500 -year return period earthquake. A push-over analysis shows bilinear behaviour between base-shear and roof displacement with yield deformation $d_{y}=46.5 \mathrm{~mm}$, preyielding stiffness $k=27300 \mathrm{kN} / \mathrm{m}$, and bilinear factor $\alpha=0.065$. The estimated linear structural fundamental period is $\sim 1.20 \mathrm{~s}$. The detailed nonlinear pushover results can be found in [19]. A damping ratio of $5 \%$ is assumed which is common for civil structures and the corresponding viscous damping coefficient $c$ is $521 \mathrm{kN} \cdot \mathrm{s} / \mathrm{m}$.

Structural displacement and acceleration response is obtained through Newmark numerical integration. The sampling frequency is $200 \mathrm{~Hz}$ for the measurement of acceleration and is $20 \mathrm{~Hz}$ for the displacement. The objective of applying the proposed SHM method is to determine the structural properties of the preyielding stiffness, bilinear factor, and yielding deformation and estimate cumulative plastic deformation and residual deformation to indicate potential structural damage. The proposed method is implemented in MATLAB.

First, the targeted structure was subjected to the 1987 Superstition Hill earthquake with peak ground acceleration (PGA) of $0.358 \mathrm{~g}$ (EQ1 in Table 1). The SHM method was first demonstrated for proof of the concept using noise-free response signals. The effect of choices of the threshold to separate linear and nonlinear half cycles is investigated. Next, the effect of measurement noise was studied by adding a white noise process to acceleration and displacement response and ground acceleration, respectively. Four noise levels of 3\%, 5\%, $10 \%$, and $20 \%$ RMS noise-to-signal ratio are considered. This 
TABLE 1: Selected 20 ground motions.

\begin{tabular}{|c|c|c|c|c|c|c|c|c|}
\hline EQ & Event & Year & $M_{W}$ & Station & $R$-distance $(\mathrm{km})$ & Soil type & Duration (s) & PGA (g) \\
\hline EQ1 & \multirow{3}{*}{ Superstition Hill } & \multirow{3}{*}{1987} & \multirow{3}{*}{6.7} & EI Centro Imp. Co. Cent & 13.9 & $\mathrm{D}$ & 40.0 & 0.358 \\
\hline EQ2 & & & & Brawley & 18.2 & $\mathrm{D}$ & 22.0 & 0.156 \\
\hline EQ3 & & & & Plaster City & 21.0 & $\mathrm{D}$ & 22.2 & 0.121 \\
\hline EQ4 & \multirow{7}{*}{ Northridge } & \multirow{7}{*}{1994} & \multirow{7}{*}{6.7} & Beverly Hills 14145 Mulhol & 19.6 & $\mathrm{C}$ & 30.0 & 0.516 \\
\hline EQ5 & & & & Canoga Park-Topanga Can & 15.8 & $\mathrm{D}$ & 25.0 & 0.356 \\
\hline EQ6 & & & & Glendale-Las Palmas & 25.4 & $\mathrm{D}$ & 30.0 & 0.206 \\
\hline EQ7 & & & & LA-Hollywood Stor. FF & 25.5 & $\mathrm{D}$ & 40.0 & 0.231 \\
\hline EQ8 & & & & N. Hollywood-Coldwater Can & 14.6 & $\mathrm{C}$ & 21.9 & 0.273 \\
\hline EQ9 & & & & LA-N Faring Rd & 23.9 & $\mathrm{D}$ & 30.0 & 0.298 \\
\hline EQ10 & & & & Sunland-Mt Gleason Ave & 17.7 & $\mathrm{C}$ & 30.0 & 0.127 \\
\hline EQ11 & \multirow{6}{*}{ Loma Prieta } & \multirow{6}{*}{1989} & \multirow{6}{*}{6.9} & Capitola & 14.5 & $\mathrm{D}$ & 40.0 & 0.529 \\
\hline EQ12 & & & & Gilroy Array \#3 & 14.4 & $\mathrm{D}$ & 39.9 & 0.555 \\
\hline EQ13 & & & & Gilroy Array \#4 & 16.1 & $\mathrm{D}$ & 40.0 & 0.417 \\
\hline EQ14 & & & & Gilroy Array \#7 & 24.2 & $\mathrm{D}$ & 40.0 & 0.226 \\
\hline EQ15 & & & & Hollister Diff. Array & 25.8 & $\mathrm{D}$ & 39.6 & 0.269 \\
\hline EQ16 & & & & Saratoga-W Valley Coll. & 13.7 & $\mathrm{C}$ & 40.0 & 0.332 \\
\hline EQ17 & \multirow{2}{*}{ Cape Mendocino } & \multirow{2}{*}{1992} & \multirow{2}{*}{7.1} & Fortuna-Fortuna Blvd & 23.6 & $\mathrm{C}$ & 44.0 & 0.116 \\
\hline EQ18 & & & & Rio Dell Overpass-FF & 18.5 & $\mathrm{C}$ & 36.0 & 0.171 \\
\hline EQ19 & \multirow{2}{*}{ Landers } & \multirow{2}{*}{1992} & \multirow{2}{*}{7.3} & Desert Hot Springs & 23.3 & $\mathrm{C}$ & 50.0 & 0.385 \\
\hline EQ20 & & & & Yermo Fire Station & 24.9 & $\mathrm{D}$ & 44.0 & 0.245 \\
\hline
\end{tabular}

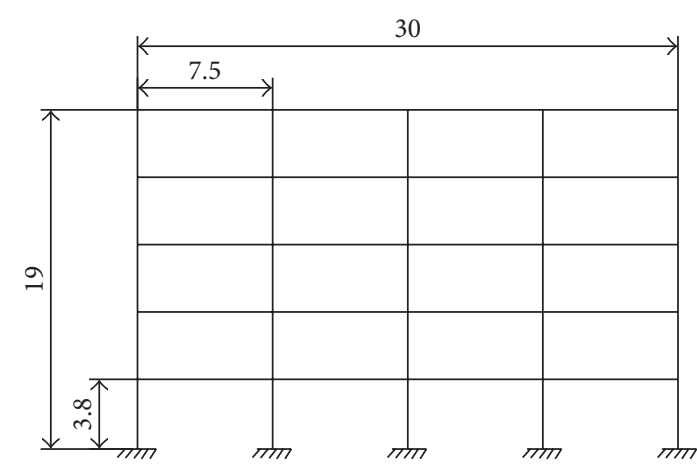

(a) Front view

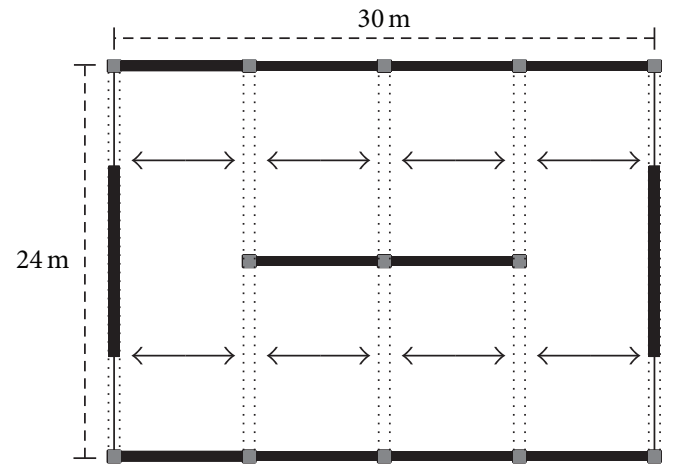

(b) Plan view

FIGURE 2: The simulated five-storey shear-type building.

case was repeated for 100 Monte-Carlo runs to find the effect of noise and the range of possible variation at the given noise level.

To assess the robustness of the proposed method over different ground motions, the simulated structures were subjected to a suite of 20 ground motions with different spectral characteristics and PGA, as shown in Table 1. These earthquake records are widely used in earthquake engineering [19]. In each case, the noise level of 10\% RMS is considered.

It is noted that in this study the 10\% RMS Gaussian white noise was selected as a base and typical noise level and added to measurements of ground acceleration, structural acceleration, and displacement because it is considered to be a normal working range for civil engineering applications [27] and big enough for typical acceleration and displacement sensors accuracy [26, 28-30]. The reason of studying different noise levels is to prove the robustness of the proposed method and clarify the sensitivity of the method to noise.

\section{Results and Discussions}

5.1. Validation of the Proposed Method Using Noise-Free Response. Simulated noise-free high-rate acceleration and low-rate displacement responses were first used as inputs to reconstruct high-rate displacement and velocity using the multirate Kalman filtering method. These reconstructed responses, together with ground and response acceleration, are input to SHM procedure.

Figure 3 plots the identified equivalent linear system stiffness $k_{l}$ and equivalent viscous damping coefficient $c_{l}$ for each half cycle versus half-cycle displacement $\Delta d$, respectively. The points in Figure 3 can be divided into two regimes 
TABLE 2: Estimations of preyielding stiffness $[\mathrm{KN} / \mathrm{m}]$ and viscous damping coefficient $[\mathrm{KN} \cdot \mathrm{s} / \mathrm{m}]$.

\begin{tabular}{lccccc}
\hline & Mean & Mean error & St. d. & 95\% confidence interval & True value \\
\hline Preyielding stiffness & 27335 & $0.1 \%$ & 271 & {$[27263,27407]$} & 27300 \\
Viscous damping coefficient & 482 & $7.5 \%$ & 108 & {$[453,510]$} & 521 \\
\hline
\end{tabular}

TABLE 3: Estimated structural performance parameters from multiphase linear regression analysis.

\begin{tabular}{lccc}
\hline Half cycle \# & Bilinear factor & Yield displacement $(\mathrm{mm})$ & Plastic displacement $(\mathrm{mm})$ \\
\hline 31 & 0.062 & 46.7 & -64.4 \\
32 & 0.061 & 47.3 & +104.7 \\
Mean & 0.062 & 47.0 & - \\
Mean error & $4.6 \%$ & $1.1 \%$ & - \\
True values & 0.065 & 46.5 & - \\
\hline
\end{tabular}

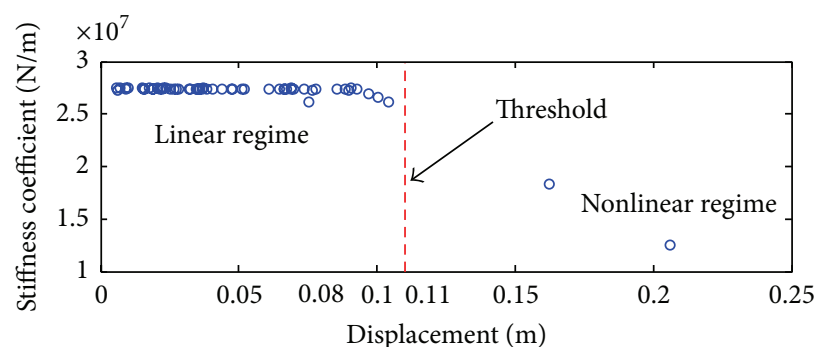

(a)

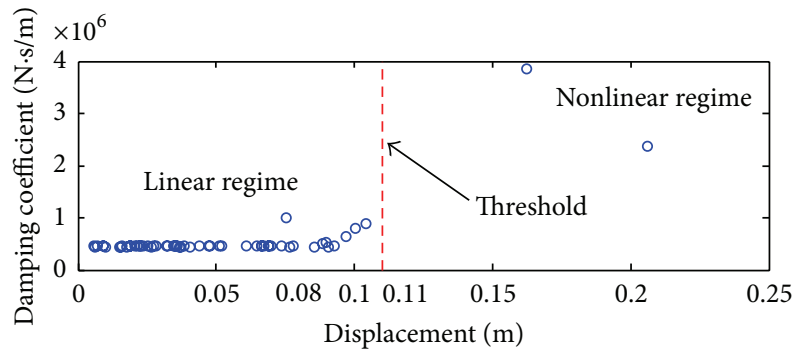

(b)

FIGURE 3: Linear regression results: (a) effective stiffness with half-cycle displacement; (b) effective viscous damping with half-cycle displacement.

according to the trend of variation. When the half-cycle displacement is small, $k_{l}$ and $c_{l}$ are nearly constant because the structure behaves linearly. Both drop rapidly as the amplitude of displacement exceeds a critical value. Therefore, Figure 3 can be used as a qualitative indicator of system linear or nonlinear behaviour during an earthquake. If all points are around a horizontal line, the structure can be viewed as linear or nearly linear. Otherwise, nonlinear deformation should be considered. Based on Figure 3, a threshold can be assigned to separate linear and nonlinear regimes. In this case, the threshold of $0.11 \mathrm{~m}$ is used and the effect of the choices will be investigated in next section.

All points in linear regions directly give estimates of preyielding stiffness and viscous damping coefficient. Table 2 gives the statistical results of these two parameters. It can be seen that the identified mean of $k_{e}$ is very close to the true model values with relative error of $0.1 \%$. Since viscous damping restoring force forms a very small part of the total restoring force, the mean estimate error of the viscous damping coefficient is a little larger but still satisfying. Overall, the results demonstrate that the proposed method can give good estimates of system preyielding stiffness and viscous damping coefficient.

Half cycles in nonlinear regime are identified using Step 2. Figure 4 shows the simulated true hysteresis loops. Figure 5 shows the identified nonlinear half cycles and multiphase linear regression approximation results. It can be seen that, using the threshold, the main nonlinear hysteretic half cycles

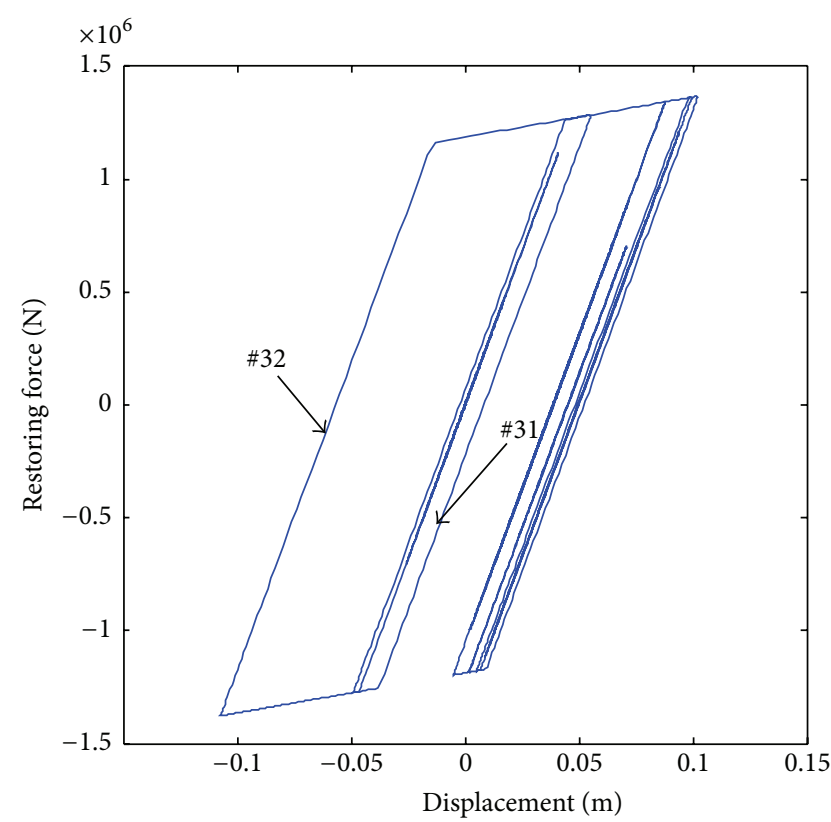

FIGURE 4: Simulated hysteresis loops.

are captured $(\# 31,32)$ that dominate the nonlinear structural behaviour.

Multiphase linear regression results approach the identified hysteresis half cycles very well. Table 3 shows the detailed 


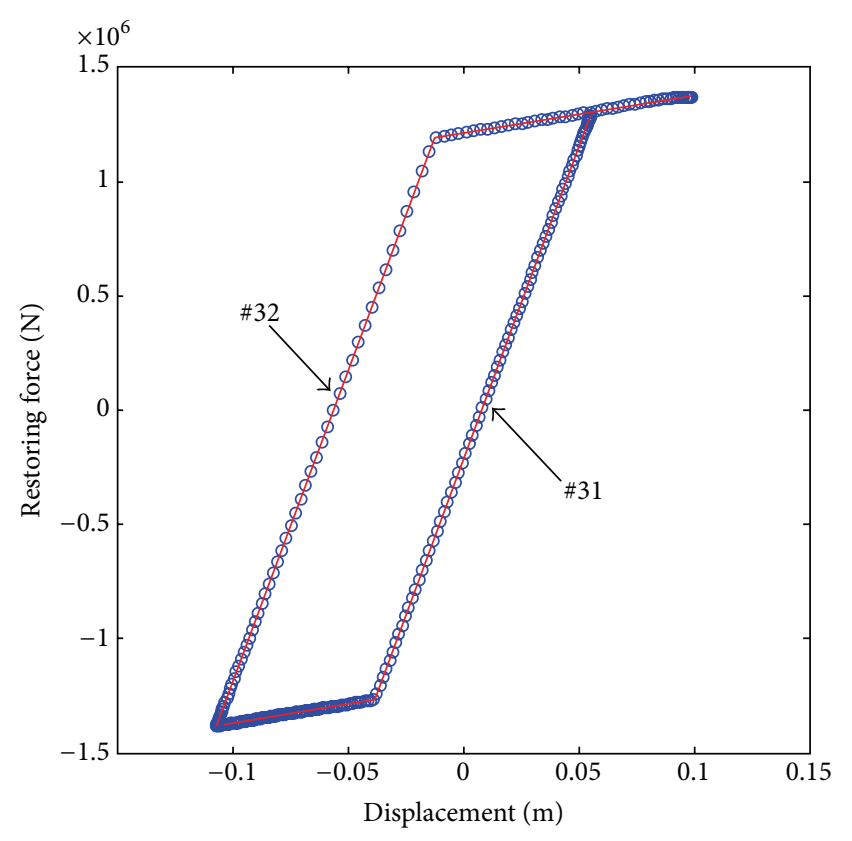

FIGURE 5: Identified nonlinear half cycles and multiphase linear regression results for 2 half cycles. The line is the identified model and the circles are the simulated data.

multiphase regression results for two half cycles, \#31 32. It can be seen that the estimated bilinear factor and yield displacement are very close to the true parameters. The derived plastic displacement in each nonlinear half cycle can be summed to obtain the cumulative plastic deformation and residual displacement. In this case, the cumulative plastic deformation is $169.1 \mathrm{~mm}$ and the residual displacement is $+40.3 \mathrm{~mm}$.

5.2. Effect of Threshold Chosen. The effect of the choice of threshold is investigated by varying its values between $0.09 \mathrm{~m}$ and $0.13 \mathrm{~m}$. The results are listed in Table 4 . It can be seen that there is little effect on the identification accuracy of the linear parameters, preyielding stiffness, and viscous damping coefficient when the threshold chosen varies from $0.09 \mathrm{~m}$ to $0.13 \mathrm{~m}$. However, identified bilinear factor and yield displacement show a larger error when the threshold is lower because some linear or nearly linear half cycles are identified as nonlinear. In this situation, multiphase linear regression will give poor results due to wrong regression model used. Thus, identification accuracy improves when only large displacement nonlinear half cycles are considered (thresholds larger than $0.11 \mathrm{~m}$ ). However, it is noted that a very large threshold will mean some large displacement half cycles lost and underestimate the cumulative plastic deformation.

5.3. Effect of Noise on Parameter Identification. Figure 6 shows the multiphase linear regression analysis results for 100 runs at different noise levels. It can be seen that as the noise level increases, the nonlinear regression accuracy and consistency both decrease. A threshold of $0.11 \mathrm{~m}$ was used in all cases.

The statistical summary of identified system parameters compared to the true model parameters is listed in Table 5. It can be seen from Table 5 and Figure 6 that the numerical accuracy of the identified parameters is generally very good and the two-step identification method proposed can give robust system performance parameters even at 10\% RMS added noise level. In particular, the identified preyielding stiffness and yield displacement are less sensitive to noise than the viscous damping coefficient and bilinear factor. Even with added 20\% RMS noise, the mean relative error of preyielding stiffness and yield displacement is within $2 \%$. Thus, the identification of preyielding stiffness and yield deformation using the proposed method is highly robust to measurement noise. The identified bilinear factor is also excellent to $10 \%$ noise and good at $20 \%$. It is more sensitive to noise due to the fact that there are far less data points in the nonlinear regime than in elastic regime, and regression analysis is sensitive to the number of data points. Identification accuracy would be improved if there were more large plastic displacements to provide a larger number of data points.

5.4. Identification Results over 20 Seismic Events. Table 6 lists the identified system parameters and damage indicators over 20 seismic events with 10\% RMS added noise. A "-" is presented where the structure is identified as remaining linear during the event. The structure was identified as remaining linear for all of EQ2, 3, 5, 6, 9, 10, 12, 14, 17, and 19, and as nonlinear for the other events. Therefore, the proposed method can directly detect whether the structure undergoes nonlinear deformation. The identified system model parameters match very well with true model parameters and demonstrate the proposed method is robust to ground motions. The method can derive two damage indicators: cumulative plastic deformation and residual deformation, used to assess structural damage severity and repair costs. For example, estimated maximum cumulative plastic deformation is $500.4 \mathrm{~mm}$ for EQ11, which indicates the structure is significantly damaged, while it is much lower for EQ7.

It is noted that there is no direct comparative assessment of the proposed method against any existing SHM techniques. The primary reason is that no prior methods split the linear half cycles from the nonlinear half cycles of response and pull out nonlinear half-cycle displacement and postyielding stiffness, except Nayyerloo et al. [19], which is a much more complex, but real-time, algorithm. Equally importantly, the work of Nayyerloo et al. [19] is restricted to fitting a Bouc-Wen model, whereas this approach is more general to any nonlinear, elastoplastic method. Finally, it is important to note that we found no prior works that directly identified nonlinear stiffness in this fashion making direct comparison very difficult for those that do address nonlinear behaviour.

Although the efficiency of the method is demonstrated using a simple closed-formed problem, the value of the proposed method can be evaluated from three perspectives. First, the key of the method is to capture half cycles and get elastoplastic properties from them. It is not dependent on a specific 
TABLE 4: Effect of threshold chosen on identification results.

\begin{tabular}{|c|c|c|c|c|}
\hline & Preyielding stiffness $(\mathrm{KN} / \mathrm{m})$ & Viscous damping $(\mathrm{KN} \cdot \mathrm{s} / \mathrm{m})$ & Yield deformation $(\mathrm{mm})$ & Bilinear factor \\
\hline True & 27300 & 521 & 46.5 & 0.065 \\
\hline \multicolumn{5}{|l|}{ Threshold $=0.09 \mathrm{~m}$} \\
\hline Mean & 27380 & 464 & 39.2 & 0.284 \\
\hline Coefficient of variation & 0.007 & 0.174 & 0.356 & 1.581 \\
\hline Mean error & $0.3 \%$ & $10.9 \%$ & $15.7 \%$ & $336.9 \%$ \\
\hline \multicolumn{5}{|l|}{ Threshold $=0.10 \mathrm{~m}$} \\
\hline Mean & 27371 & 468 & 46.7 & 0.079 \\
\hline Coefficient of variation & 0.007 & 0.176 & 0.010 & 0.702 \\
\hline Mean error & $0.3 \%$ & $10.2 \%$ & $0.4 \%$ & $21.5 \%$ \\
\hline \multicolumn{5}{|l|}{ Threshold $=0.11 \mathrm{~m}$} \\
\hline Mean & 27335 & 482 & 47.0 & 0.062 \\
\hline Coefficient of variation & 0.010 & 0.224 & 0.008 & 0.008 \\
\hline Mean error & $0.1 \%$ & $7.5 \%$ & $1.1 \%$ & $4.6 \%$ \\
\hline \multicolumn{5}{|l|}{ Threshold $=0.12 \mathrm{~m}$} \\
\hline Mean & 27335 & 482 & 47.0 & 0.061 \\
\hline Coefficient of variation & 0.010 & 0.224 & 0.008 & 0.008 \\
\hline Mean error & $0.1 \%$ & $7.5 \%$ & $1.1 \%$ & $6.2 \%$ \\
\hline \multicolumn{5}{|l|}{ Threshold $=0.13 \mathrm{~m}$} \\
\hline Mean & 27335 & 482 & 47.0 & 0.061 \\
\hline Coefficient of variation & 0.010 & 0.224 & 0.008 & 0.008 \\
\hline Mean error & $0.1 \%$ & $7.5 \%$ & $1.1 \%$ & $6.2 \%$ \\
\hline
\end{tabular}

TABLE 5: Statistical summary of estimated system parameters for 100 Monte-Carlo runs (threshold $=0.11 \mathrm{~m}$ ).

\begin{tabular}{|c|c|c|c|c|}
\hline & Preyielding stiffness $(\mathrm{KN} / \mathrm{m})$ & Viscous damping $(\mathrm{KN} \cdot \mathrm{s} / \mathrm{m})$ & Bilinear factor & Yield deformation (mm) \\
\hline Actual model & 27300 & 521 & 0.065 & 46.5 \\
\hline \multicolumn{5}{|l|}{ Noise-free } \\
\hline Mean & 27335 & 482 & 0.062 & 47.0 \\
\hline Coefficient of variation & 0.0000 & 0.0000 & 0.0000 & 0.0000 \\
\hline Mean error & $0.1 \%$ & $7.5 \%$ & $4.6 \%$ & $1.1 \%$ \\
\hline \multicolumn{5}{|l|}{ 3\% RMS white noise } \\
\hline Mean & 27335 & 481 & 0.062 & 47.1 \\
\hline Coefficient of variation & 0.0000 & 0.0124 & 0.0212 & 0.002 \\
\hline Mean error & $0.1 \%$ & $7.7 \%$ & $4.6 \%$ & $1.3 \%$ \\
\hline \multicolumn{5}{|l|}{ 5\% RMS white noise } \\
\hline Mean & 27336 & 482 & 0.064 & 47.2 \\
\hline Coefficient of variation & 0.0018 & 0.0210 & 0.0345 & 0.0035 \\
\hline Mean error & $0.1 \%$ & $7.5 \%$ & $1.5 \%$ & $1.5 \%$ \\
\hline \multicolumn{5}{|l|}{$10 \%$ RMS white noise } \\
\hline Mean & 27237 & 474 & 0.071 & 47.3 \\
\hline Coefficient of variation & 0.0082 & 0.0625 & 0.0706 & 0.0080 \\
\hline Mean error & $0.2 \%$ & $9.0 \%$ & $9.2 \%$ & $1.7 \%$ \\
\hline \multicolumn{5}{|l|}{$20 \%$ RMS white noise } \\
\hline Mean & 26825 & 440 & 0.092 & 46.9 \\
\hline Coefficient of variation & 0.0142 & 0.1293 & 0.0855 & 0.0130 \\
\hline Mean error & $1.7 \%$ & $15.5 \%$ & $41.5 \%$ & $0.9 \%$ \\
\hline
\end{tabular}




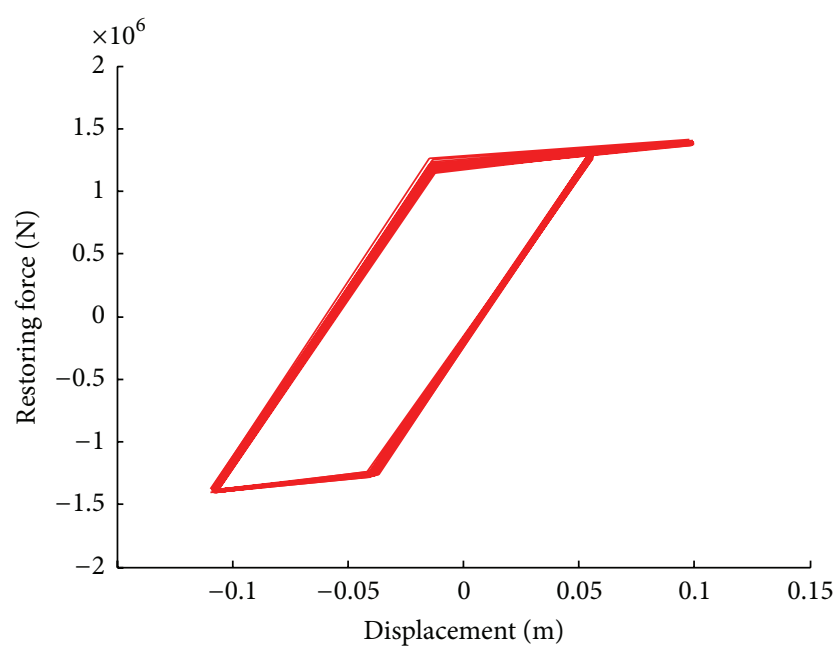

(a) 3\% RMS noise

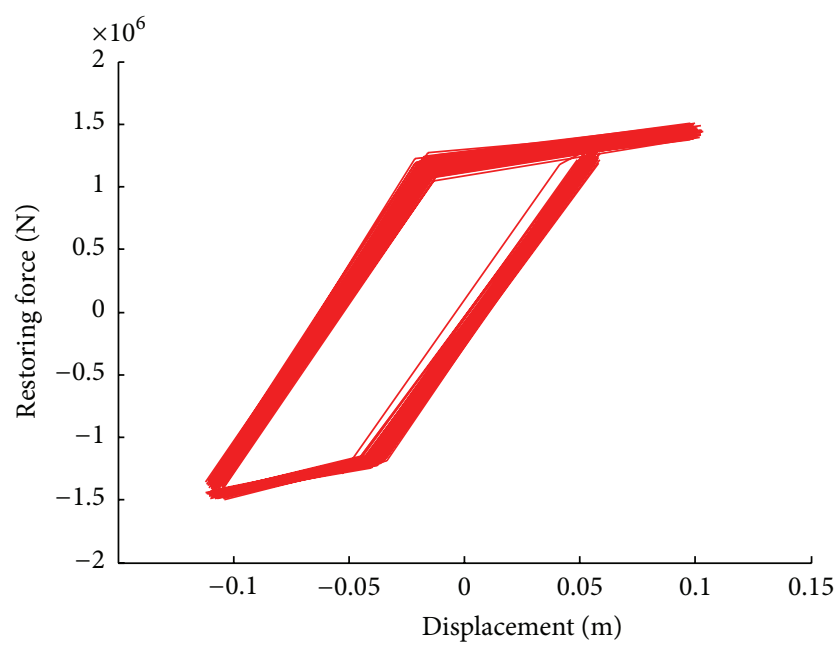

(c) $10 \%$ RMS noise

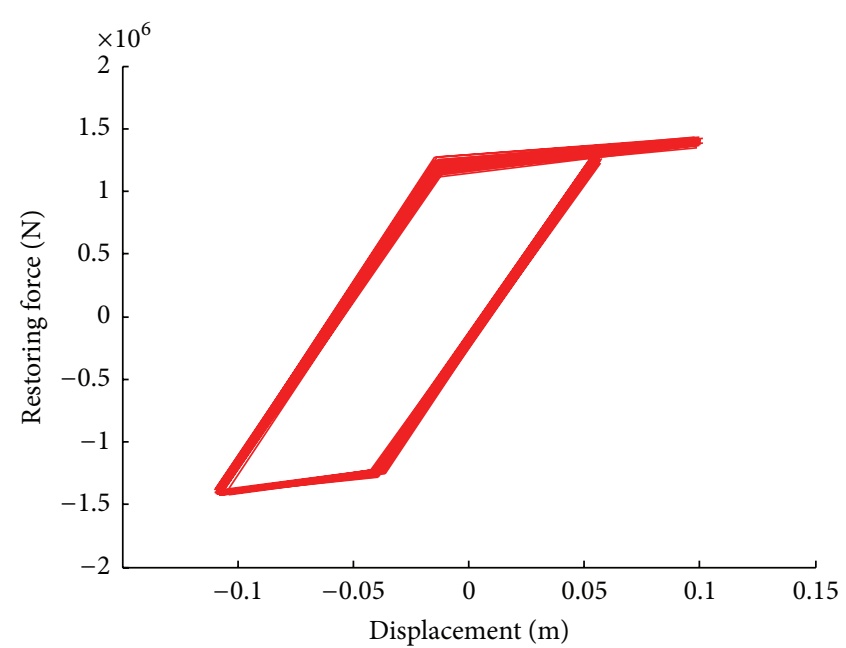

(b) $5 \%$ RMS noise

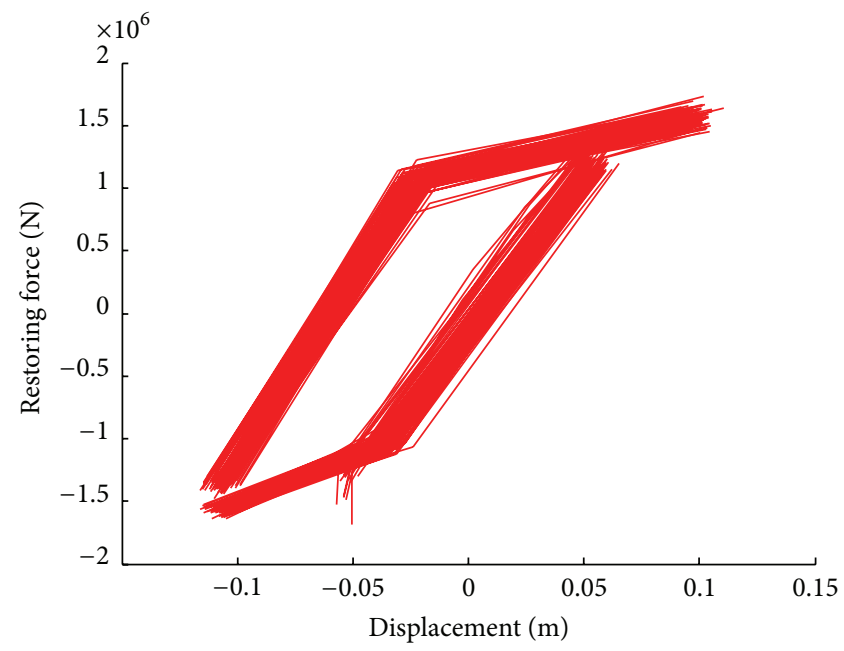

(d) $20 \%$ RMS noise

FIGURE 6: Identified nonlinear half cycles and multiphase linear regression results.

mechanics model but instead relies on direct measurements and identified half cycles. Thus, the proposed method can be generalized to identify similar hysteretic systems, where nonlinear half-cycle shape can be approximated by a bilinear shape. Second, the identification procedure is carried out from half cycle to half cycle. It thus can capture time-variant physical parameters to characterize a degrading hysteretic system. Third, the identification procedure is essentially performed storey by storey. Therefore, the proposed method is completely generalizable to overall nonlinear multistorey structures and a wide range of mechanics.

However, the robustness of the method to real data is still unproven since the significant plastic real data is available in a limited way. The proposed identification procedure remains to be experimentally validated and further tested before implementation in the field for final performance evaluation.

\section{Conclusions}

This paper develops a novel SHM method for civil structures using hysteresis loops reconstructed from seismic response data. Low-rate sampled displacement and high-rate sample acceleration are fused by the multirate Kalman filtering method to construct high quality hysteresis loops. A twostep regression analysis based method is developed to identify nonlinear system parameters and extract damage indicators related to structural health status and repair costs.

To apply linear and nonlinear regression analysis, system hysteretic loops are split into many half cycles where restoring force is a monotone function of displacement. A special nonlinear regression method, named multiphase linear regression, is used to directly estimate turning points and postyielding stiffness. This approach significantly simplifies the nonlinear system identification procedure for obtaining preyielding stiffness, viscous damping coefficient, postyielding stiffness, and the yield displacement simultaneously.

From the results obtained in this study, it is clear that the proposed method is feasible and effective for nonlinear system identification and damage indicator extraction. When no measurement noise is added, the proposed SHM procedure can identify system physical parameters with very high 
TABLE 6: Identification results for 20 seismic events with 10\% RMS added noise.

\begin{tabular}{|c|c|c|c|c|c|c|}
\hline Event \# & $\begin{array}{c}\text { Preyielding } \\
\text { stiffness }(\mathrm{KN} / \mathrm{m})\end{array}$ & $\begin{array}{c}\text { Yield } \\
\text { displacement } \\
(\mathrm{mm})\end{array}$ & Bilinear factor & $\begin{array}{c}\text { Viscous damping } \\
\text { coefficient } \\
(\mathrm{KN} \cdot \mathrm{s} / \mathrm{m})\end{array}$ & $\begin{array}{l}\text { Estimated cumulative } \\
\text { plastic deformation } \\
(\mathrm{mm})\end{array}$ & $\begin{array}{l}\text { Residual } \\
\text { deformation } \\
(\mathrm{mm})\end{array}$ \\
\hline EQ1 & 27237 & 47.3 & 0.071 & 474 & 168.1 & 42.0 \\
\hline EQ2 & 27421 & - & - & 448 & - & - \\
\hline EQ3 & 27218 & - & - & 500 & - & - \\
\hline EQ4 & 26870 & 51.0 & 0.108 & 544 & 391.5 & 54.7 \\
\hline EQ5 & 26971 & - & - & 557 & - & - \\
\hline EQ6 & 28119 & - & - & 480 & - & - \\
\hline EQ7 & 27411 & 45.8 & 0.141 & 475 & 21.1 & 20.0 \\
\hline EQ8 & 26967 & 46.0 & 0.200 & 577 & 214.7 & 33.4 \\
\hline EQ9 & 27622 & - & - & 461 & - & - \\
\hline EQ10 & 27531 & - & - & 453 & - & - \\
\hline EQ11 & 26723 & 46.7 & 0.154 & 512 & 500.4 & 9.3 \\
\hline EQ12 & 27571 & - & - & 453 & - & - \\
\hline EQ13 & 27346 & 44.6 & 0.131 & 468 & 198.1 & 30.0 \\
\hline EQ14 & 27819 & - & - & 478 & - & - \\
\hline EQ15 & 26976 & 47.1 & 0.112 & 506 & 98.3 & 60.8 \\
\hline EQ16 & 27016 & 47.4 & 0.123 & 521 & 368.0 & 91.9 \\
\hline EQ17 & 27470 & - & - & 463 & - & - \\
\hline EQ18 & 27289 & 46.6 & 0.126 & 480 & 234.6 & 64.0 \\
\hline EQ19 & 27540 & - & - & 459 & - & - \\
\hline EQ20 & 26974 & 46.9 & 0.128 & 503 & 307.7 & 97.9 \\
\hline True & 27300 & 46.5 & 0.065 & 521 & & \\
\hline
\end{tabular}

precision. Even with $10 \%$ or $20 \%$ RMS noise, the method identifies some system parameters with good precision and has good repeatability and robustness. The proposed method is also robust over different ground motions and can directly detect whether nonlinear response occurs.

Overall, the proposed SHM method is simple, direct, and robust. The identification procedure is performed time segment by time segment, which provides the possibility for it to be implemented in real-time or near real-time. Although the concept is proven focusing on structural systems that display nondegraded hysteresis behaviour, it can be easily extended to degrading structures and arbitrary changes in system parameters, including degradation.

\section{Conflict of Interests}

The authors declare that there is no conflict of interests regarding the publication of this paper.

\section{Acknowledgments}

The present work was supported in part by China Scholarship Council for postdoctoral fellow (no. 201203070008) and National Science Foundation of China (no. 11372246). The authors would like to thank the reviewers for their comments that help improve the paper.

\section{References}

[1] F. Naeim, "Real-time damage detection and performance evaluation for buildings," in Earthquakes and Health Monitoring of Civil Structures, pp. 167-196, Springer, Dordrecht, The Netherlands, 2013.

[2] G. Hearn and R. B. Testa, "Modal analysis for damage detection in structures," Journal of Structural Engineering, vol. 117, no. 10, pp. 3042-3063, 1991.

[3] S. W. Doebling, C. R. Farrar, and M. B. Prime, "A summary review of vibration-based damage identification methods," Shock and Vibration Digest, vol. 30, no. 2, pp. 91-105, 1998.

[4] B. Peeters, J. Maeck, and G. De Roeck, "Vibration-based damage detection in civil engineering: excitation sources and temperature effects," Smart Materials and Structures, vol. 10, no. 3, article 518, 2001.

[5] J. M. Ko and Y. Q. Ni, "Technology developments in structural health monitoring of large-scale bridges," Engineering Structures, vol. 27, no. 12, pp. 1715-1725, 2005.

[6] P. C. Chang, A. Flatau, and S. C. Liu, "Review paper: health monitoring of civil infrastructure," Structural Health Monitoring, vol. 2, no. 3, pp. 257-267, 2003.

[7] G. Park, H. H. Cudney, and D. J. Inman, "Impedance-based health monitoring of civil structural components," Journal of Infrastructure Systems (ASCE), vol. 6, no. 4, pp. 153-160, 2000.

[8] A. Raghavan and C. E. S. Cesnik, "Review of guided-wave structural health monitoring," The Shock and Vibration Digest, vol. 39, no. 2, pp. 91-114, 2007. 
[9] Z. Hou, M. Noori, and R. S. Amand, "Wavelet-based approach for structural damage detection," Journal of Engineering Mechanics, vol. 126, no. 7, pp. 677-683, 2000.

[10] J. N. Yang, Y. Lei, S. Lin, and N. Huang, "Hilbert-Huang based approach for structural damage detection," Journal of Engineering Mechanics, vol. 130, no. 1, pp. 85-95, 2004.

[11] J.-S. Lin and Y. G. Zhang, "Nonlinear structural identification using extended Kalman filter," Computers and Structures, vol. 52, no. 4, pp. 757-764, 1994.

[12] T. Sato and K. Qi, "Adaptive $H_{\infty}$ filter: its application to structural identification," Journal of Engineering Mechanics, vol. 124, no. 11, pp. 1233-1240, 1998.

[13] C.-H. Loh, C.-Y. Lin, and C.-C. Huang, "Time domain identification of frames under earthquake loadings," Journal of Engineering Mechanics, vol. 126, no. 7, pp. 693-703, 2000.

[14] J. G. Chase, K. L. Hwang, L. R. Barroso, and J. B. Mander, "A simple LMS-based approach to the structural health monitoring benchmark problem," Earthquake Engineering and Structural Dynamics, vol. 34, no. 6, pp. 575-594, 2005.

[15] J. G. Chase, H. A. Spieth, C. F. Blome, and J. B. Mander, "LMSbased structural health monitoring of a non-linear rocking structure," Earthquake Engineering and Structural Dynamics, vol. 34, no. 8, pp. 909-930, 2005.

[16] J. N. Yang, S. L. Lin, H. W. Huang, and L. Zhou, "An adaptive extended Kalman filter for structural damage identification," Structural Control and Health Monitoring, vol. 13, no. 4, pp. 849867, 2006.

[17] M. Wu and A. W. Smyth, "Application of the unscented Kalman filter for real-time nonlinear structural system identification," Structural Control and Health Monitoring, vol. 14, no. 7, pp. 971990, 2007.

[18] Y. Chen and M. Q. Feng, "Structural health monitoring by recursive bayesian filtering," Journal of Engineering Mechanics, vol. 135, no. 4, pp. 231-242, 2009.

[19] M. Nayyerloo, J. G. Chase, G. A. MacRae, and X.-Q. Chen, "Lms-based approach to structural health monitoring of nonlinear hysteretic structures," Structural Health Monitoring, vol. 10, no. 4, pp. 429-444, 2011.

[20] C. Christopoulos, S. Pampanin, and M. J. N. Priestley, "Performance-based seismic response of frame structures including residual deformations, part I: single-degree of freedom systems," Journal of Earthquake Engineering, vol. 7, no. 1, pp. 97-118, 2003.

[21] S. Pampanin, C. Christopoulos, and M. J. N. Priestley, "Performance-based seismic response of frame structures including residual deformations. Part II: multi-degree of freedom systems," Journal of Earthquake Engineering, vol. 7, no. 1, pp. 119147, 2003.

[22] J. E. Stephens and J. T. P. Yao, "Damage assessment using response measurements," Journal of Structural Engineering, vol. 113, no. 4, pp. 787-801, 1987.

[23] S. Toussi and J. T. P. Yao, "Hysteresis identification of existing structures," Journal of Engineering Mechanics, vol. 109, no. 5, pp. 1189-1202, 1983.

[24] W. D. Iwan and A. O. Cifuentes, "A model for system identification of degrading structures," Earthquake Engineering and Structural Dynamics, vol. 14, no. 6, pp. 877-890, 1986.

[25] S. R. Subia and M. L. Wang, "Nonlinear hysteresis curve derived by direct numerical investigation of acceleration data," Soil Dynamics and Earthquake Engineering, vol. 14, no. 5, pp. 321330, 1995.
[26] W.-S. Chan, Y.-L. Xu, X.-L. Ding, Y.-L. Xiong, and W.-J. Dai, "Assessment of dynamic measurement accuracy of GPS in three directions," Journal of Surveying Engineering, vol. 132, no. 3, pp. 108-117, 2006.

[27] A. Smyth and M. L. Wu, "Multi-rate Kalman filtering for the data fusion of displacement and acceleration response measurements in dynamic system monitoring," Mechanical Systems and Signal Processing, vol. 21, no. 2, pp. 706-723, 2007.

[28] C. E. Hann, I. Singh-Levett, B. L. Deam, J. B. Mander, and J. G. Chase, "Real-time system identification of a nonlinear fourstory steel frame structure-application to structural health monitoring," IEEE Sensors Journal, vol. 9, no. 11, pp. 1339-1346, 2009.

[29] H. S. Lee, Y. H. Hong, and H. W. Park, "Design of an FIR filter for the displacement reconstruction using measured acceleration in low-frequency dominant structures," International Journal for Numerical Methods in Engineering, vol. 82, no. 4, pp. 403434, 2010.

[30] Y. H. Hong, S. G. Lee, and H. S. Lee, "Design of the FEM-FIR filter for displacement reconstruction using accelerations and displacements measured at different sampling rates," Mechanical Systems and Signal Processing, vol. 38, no. 2, pp. 460-481, 2013.

[31] A. O. Cifuentes and W. D. Iwan, "Nonlinear system identification based on modelling of restoring force behaviour," Soil Dynamics and Earthquake Engineering, vol. 8, no. 1, pp. 2-8, 1989.

[32] D. Benedetti and M. P. Limongelli, "A model to estimate the virgin and ultimate effective stiffnesses from the response of a damaged structure to a single earthquake," Earthquake Engineering \& Structural Dynamics, vol. 25, no. 10, pp. 1095$1108,1996$.

[33] W. D. Iwan, "R-SHAPE: a real-time structural health and performance evaluation system," in Proceedings of the US-Europe Workshop on Sensors and Smart Structures Technology, pp. 33$38,2002$.

[34] K. Worden, "Data processing and experiment design for the restoring force surface method, part I: integration and differentiation of measured time data," Mechanical Systems and Signal Processing, vol. 4, no. 4, pp. 295-319, 1990.

[35] F. L. Lewis, L. Xie, and D. Popa, Optimal and Robust Estimation: With an Introduction to Stochastic Control Theory, CRC Press, 2008.

[36] G. A. F. Seber and A. J. Lee, Linear Regression Analysis, John Wiley \& Sons, 2012.

[37] J. D. Hodon, "Fitting segmented surveys whose join points have to be estimated," Journal of the American Statistical Association, vol. 61, pp. 1097-1129, 1966.

[38] P. M. Lerman, "Fitting segmented regression models by grid search," Journal of the Royal Statistical Society, Series C: Applied Statistics, vol. 29, no. 1, pp. 77-84, 1980.

[39] J. Cologne and R. Sposto, "Smooth piecewise linear regression splines with hyperbolic covariates," Journal of Applied Statistics, vol. 21, no. 4, pp. 221-233, 1994.

[40] E. Stoimenova, M. Datcheva, and T. Schanz, "Application of two-phase regression to geotechnical data," Pliska Studia Mathematica Bulgarica, vol. 16, pp. 245-257, 2004. 

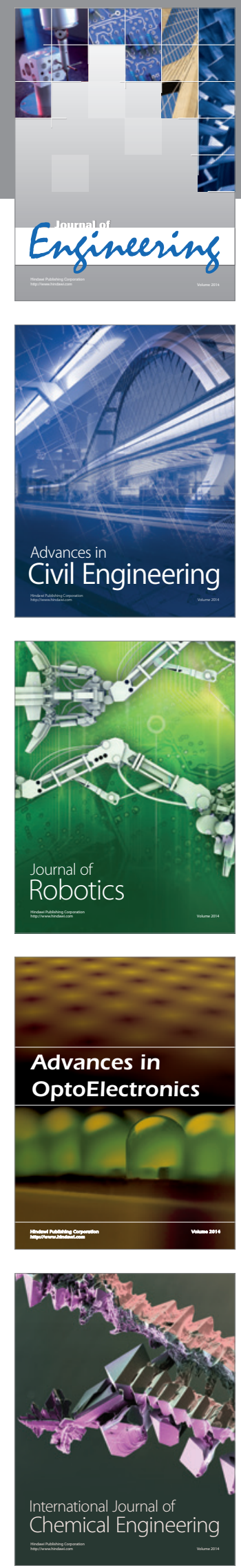

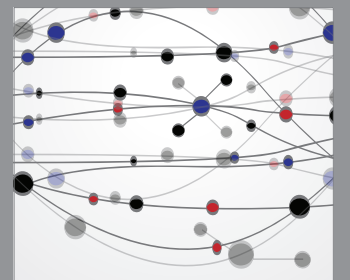

The Scientific World Journal
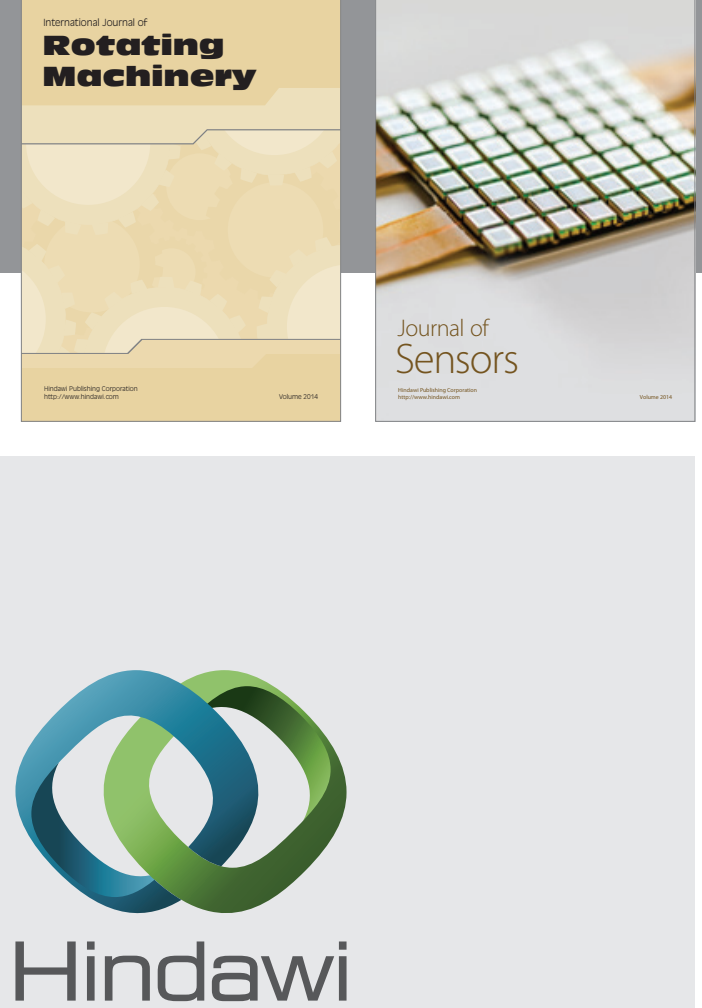

Submit your manuscripts at http://www.hindawi.com
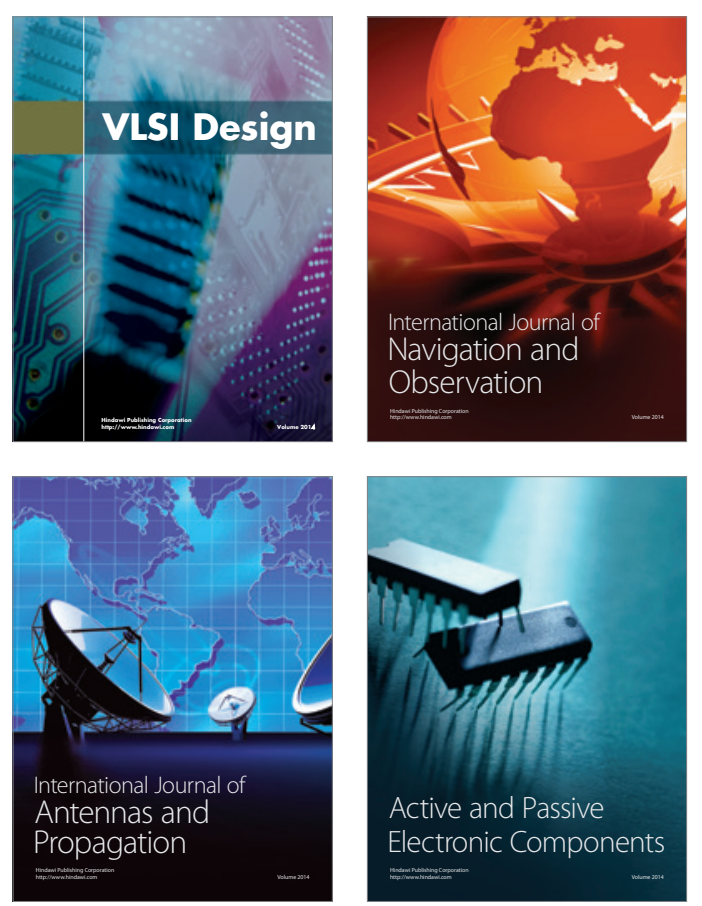
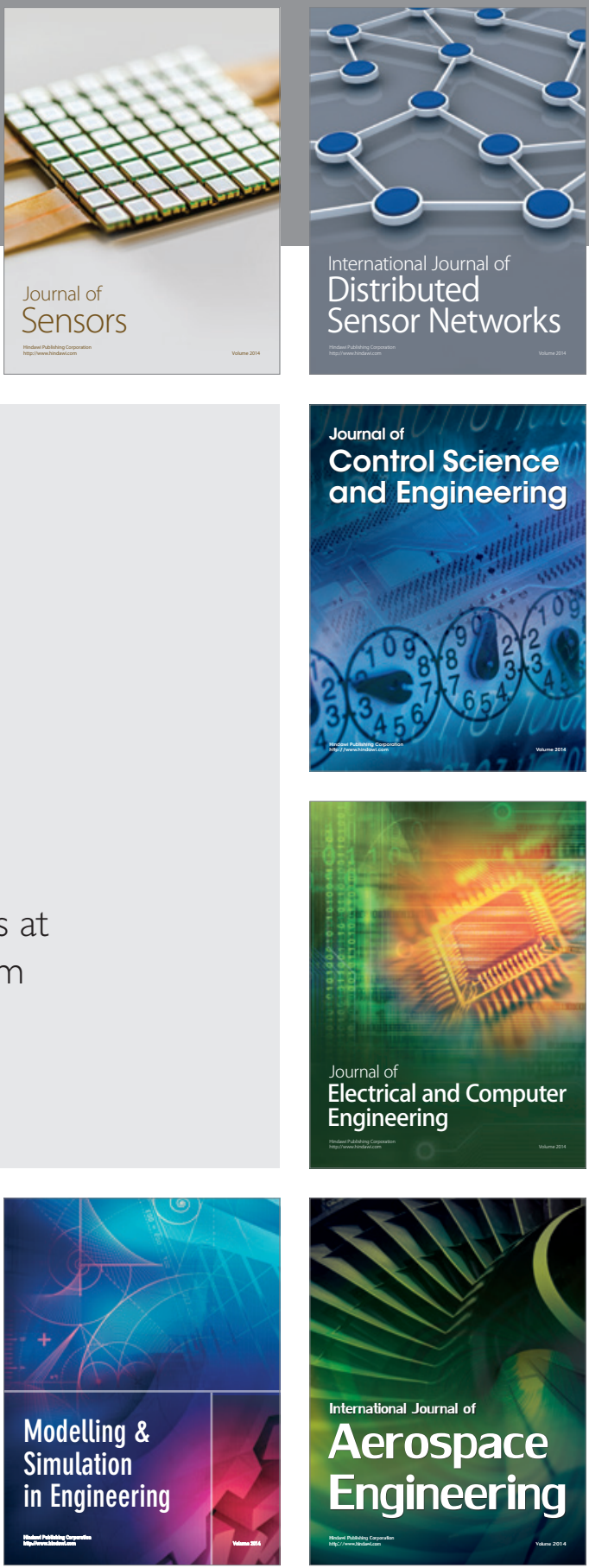

Journal of

Control Science

and Engineering
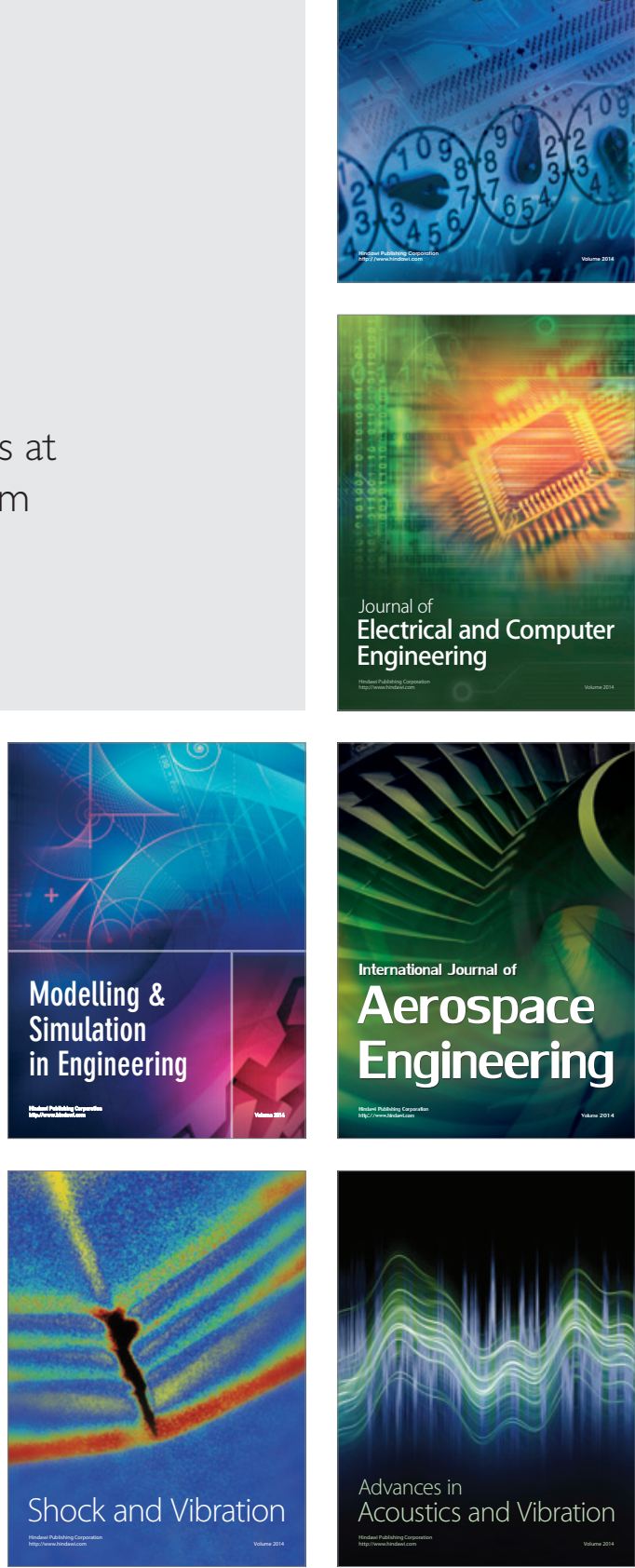